When Mr. Lockyer first pointed out his lines of coloured suns converging towards Krakatâ, the data were too scanty for him to recognize that the apparent line through Ceylon, Ongole, and Madras, was due to a widening of the main east to west stream after its first circuit of the globe. As far as the motion of this stream was indicated by African and South American observations, he was perfectly correct, though nothing was previously known as to its velocity or even actual existence. The march of the optical phenomena which is shown in Mr. Russell's maps is indeed the only direct evidence we have of the fact that at 100,000 feet above the earth in the immediate vicinity of the equator, the air in August, and probably, as Mr. Archibald shows, at other times, moves in a rapid and constant current from east to west. Both in Section III. (b) and Section VII. he discusses this question in detail, and shows its agreement with the theory of the general circulation of the atmosphere, as well as the motions of the upper clouds as far as they have been observed.

In Section IV., Mr. Archibald investigates the height of the stratum, from observations in all parts of the world where the durations of the primary or secondary glow have been recorded with any attempt at accuracy. Proceeding on the hypothesis that the primary glow was a first reflection of the sun's rays by the stratum, and the secondary a reflection of the primary glow, for which ample evidence is adduced, he concludes that the height of the upper or middle part of the stratum above the earth, diminished from I2I,000 feet in August I883, to 64,000 in January 1884 , the lower limits being practically indeterminate. Also, since from Dr. Riggenbach's and Mr. Clark's observations, the glows continued less brilliantly and less prolonged after the first few months right up to the end of 1885 , while a decided minimum in the duration, and therefore presumably the height of the reflecting layer, was reached in April I 884; the important conclusion is arrived at, that by that date the larger and more effectively reflecting particles had descended to a lower level, leaving the finest particles suspended at nearly the same elevation as at first. This is further corroborated by the remarkable fact that the large corona reached its maximum intensity during the same month.

In Section V., Mr. Russell gives an interesting list of former eruptions and accompanying atmospheric effects, similar in many respects to those under discussion. During 1783 and 1831 , the dates of the famous eruptions of Skaptar Jökull and Graham's Island, \&c., and the two years of perhaps the greatest eruptive activity antecedent to that of Krakatão, the after-glows and other optical effects were most conspicuous, and from an examination of other eruptions and sequelæ, the general correspondence between the two phenomena seems fairly proven.

Section VI. is a résumé of opinions collected by $\mathrm{Mr}$. Archibald, against and in favour of the volcanic origin of the phenomena. Besides its value in exhibiting every aspect of the question, it affords a curious illustration of the narrowness and breadth of human imagination, especially when dealing with phenomena whose universality and minor details were at first only partially realized.

Finally, in Section VII., Mr. Archibald gives a general analysis of the connection between all the optical phenomena and the eruptions of Krakatã both in May and August, in which the various objections on the ground of the initially rapid transmission of the appearances, insufficiency of fine solid ejecta, length of time of its suspension, and the occurence of apparently similar phenomena on dates previous to the great August eruption are discussed in turn. The time of suspension of the finest dust in particular, is shown-by an application of Prof. Stokes's formula,

${ }^{\tau}$ Where $\sigma, \rho$, are the densities of the particle and the fluid respectively, $a$ the radius of the particle (supposed spherical), and $\mu^{\prime}$ the index of friction $=\underline{\mu}$, where $\mu$ is the coefficient of viscosity. Its value is either $\left(0^{\circ} 116\right)^{2}$ or $\left(\stackrel{\rho}{0} 1_{4}\right)^{2}$.
$\mathrm{V}=\frac{2 g}{9 \mu^{\prime}}\left(\frac{\sigma}{\rho}-\mathrm{I}\right) a^{2}$, for the velocity of a small particle descending in air, and in which viscosity is properly considered-to he over two years between 50,000 and Ino,000 feet, even assuming the particles to be spherical, which is the most unfavourable supposition. If, as is most probable, they were thin plates, the time would be much longer. A final summary is then given of the direct and local connection between the optical phenomena and the eruptions both of May and August, which the subsequent discovery of the relative though minor importance of the May eruption rendered necessary.

In Part V., Mr. Whipple discusses the somewhat sparse data which show that a magnetic disturbance was generated by Krakatao and travelled round the world at a rate varying from 760 to 900 miles per hour, but the data are too uncertain to allow any definite conclusions to be drawn.

We cannot conclude without drawing attention to the fact that the study of the Krakatã sequelæ has not merely enlarged our conceptions of volcanic powers and the continuity of atmospheric circulation, as well as yielded positive information of great value to different branches of science, but has opened up fresh problems in optical and meteorological physics, the attack and solution of which will stimulate research as well as materially advance the boundaries of our present knowledge of these subjects.

\section{SCIENCE AND THE REPORT OF THE} EDUCATION COMMISSION.

THE Final Report of the Commissioners on the Elementary Education Acts, which has excited so much attention of late, deserves to be noticed from a point of view other than any that has yet been taken-that is, the attitude of the Commission towards the teaching of science in elementary schools. In a rather lengthy chapter on "Manual and Technical Instruction," the ground taken by the Commissioners is very clear. The teaching of science in our elementary schools, they say, is yet in its infancy. The importance of science teaching has been so far recognized that simple object-lessons are obligatory in all infant schools. This is a mode of teaching which the Report recommends to be extended. Thus in agricultural districts arrangements could be made for giving practical instruction of the simplest character in the principles of agriculture, the growth and food of plants, and their diseases; and similar instruction in the elements of dairy work might be given to the girls in these districts. The point here laid stress on is one that everybody who knows anything of former attempts to teach science to the children in Board-schools will feel the need of. Science, the Commissioners emphatically say, can never be taught to children out of books alone. No doubt much useful and entertaining knowledge is taken from text-books on science by children; but, to use the words of the Report, the true learning of science cannot be said to begin till the learners are taught to use their own senses in the study, and to rest their acceptance of scientific truth, even the most elementary, not on what they are told, but on evidence supplied by their own observation. To show the curious system of instruction pursued in our schools, it is worth while mentioning that though those simple object-lessons which lie, we are told, at the foundation of scientific instruction are compulsory in infant schools, yet immediately the child leaves the infant school they are discontinued until he reaches Standard V., after which, if he ever gets any scientific teaching, it is out of books alone. One witness considered it ridiculous that English is compulsory and elementary science optional, for, he said, English includes grammar and recitation for boys, the latter of which, he thinks, is far less likely to be useful in a manufacturing district than 
elementary science. The preponderance of opinion amongst the teachers examined is that no subject is better calculated to awaken the interest and the intelligence of the scholars than science. So far as the present teaching of elementary science is concerned, it is in a most unsatisfactory condition. Mr. J. F. Buckmaster says that, in comparison with forty years ago, this department of school work has retrograded ; and Sir Henry Roscoe agrees with the statement that the teaching of this subject is falling off. According to the latter witness, our system of education is intended to form clerks and not artisans: it is purely a literary system; and if we wish to preserve our manufacturing supremacy it must be changed. In fact, whatever has been done by the manufacturers and artisans of this country is owing in no degree whatever to the educational system, which rather retards industrial progress than otherwise; whilst on the Continent, where manufactures have made such strides of late, everything is owing to the technical schools and the scientific training of those intended for artisans. The vast majority of Board-school boys are intended for the workshop rather than the office: why, then, not fit them for the ordinary duties of life? If this be the object of elementary education--that is, the fitting of scholars in general for those duties which they will most probably be called on to perform-then, the Report says, elementary instruction in science is only second in importance to elementary instruction in reading, writing, and arithmetic. But the fact is, that though girls get some kind of training in, for example, needlework and cookery, there is no such thing as technical instruction for boys. Science, especially mathematical, mechanical, and physical science, is not only the foundation, but an essential part of technical instruction. With regard, however, to the teaching of science, certain warnings are necessary. In the first place, science teaching should not be allowed to interfere with the scholar's general instruction-that is, it should not be introduced too early in life. In the next place, the average teacher is useless as a science master. Even when by previous training the teacher is suited, he has scarcely time to devote to the preparation necessary to lecture clearly and to perform experiments accurately and neatly. Therefore, the Report suggests, the example of London, Liverpool, and Birmingham should be followed by School Boards, in engaging the services of a skilled science lecturer, who will go from school to school in a specified district. For example, in Birmingham, according to the evidence of Dr. Crosskey, the Chairman of the School Management Committee of that town, the demonstrator or an assistant visits each boys' and girls' department once a fortnight. He takes four departments a day, two in the morning and two in the afternoon. Two and a half hours a fortnight are given to science. The class teacher is present during the lecture, and recapitulates it to his scholars, who are bound to bring him written answers to questions thereon. Mechanics or elementary natural philosophy are the favourite subjects with boys,--sometimes they are taught electricity and magnetism; and the girls, domestic economy, considered as the application of chemistry and physiology to the explanation of matters of home life, and sometimes animal physiology. Not only have very great results been achieved by this system in the percentage of passes, but it is noticeable that the attendance is always largest on "science" days. Three years ago a lecturer was appointed for the East End of London, and he had at one time as many as two thousand boys under instruction in mechanics alone. 'The work has been so successful that three assistants have been appointed. Many witnesses justly complained of the kind of examination papers set in elementary science. One paper of questions is given at length in the Report. It is for boys of the Fifth Standard--that is, for boys between eleven and twelve-and consists of seven questions, of which a specimen, taken at random, may be given: "Quest. 2. In what bodies may you say that molecular attraction is balanced by the repulsive force of heat?" and written answers had to be given. Hence the suggestion of many experienced witnesses that younger children should be examined orally is taken up and recommended by the Commission.

Our system, or rather want of system, of education in elementary science is spoken of by the Commission as introductory to the wider subject of manual and technical instruction, to which they devote many pages of their Report. Into this we shall not follow them, but content ourselves by quoting a few sentences from the Report. "If it should be thought that children ought to receive some instruction in manual employment, other than that which the elementary schools available for their use can give, we are of opinion that the best way of meeting the need would be through the establishment of a workshop in connection with some higher institution, which might be willing to receive into the workshop boys of exceptional ability, or others to whom it was considered desirable to give this instruction. One such central institution could do its work better and cheaper than a number of scattered institutions, whilst nothing could be easier than to make arrangements for attendance at this central workshop being substituted on one or two afternoons in the week for attendance at the elementary school." To illustrate what might be done in this way, the case of the Seventh Standard School at Birmingham is quoted. This is to some extent a technical school, and no pupil is admitted unless he has previously passed in Standard VI. The subjects taught are reading, writing, and arithmetic, according to the Code ; and, in addition, mathematics, plane geometry and projection, machine construction and drawing, magnetism and electricity, theoretical and practical chemistry, freehand drawing, and the manipulation of wood-working tools. These subjects are not generally taught to all pupils, but are divided into three divisions, to one of which, as a rule, the student confines his attention. The first division is the machine construction division, and includes mathematics, projection, machine construction, electricity, freehand drawing, and workshop; the second division is the chemistry division, and includes mathematics, projection, chemistry (theoretical and practical), freehand drawing, and workshop; the third division, the electricity division, includes mathematics, projection, theoretical chemistry, electricity, freehand drawing, and workshop. In the second year (the course is three years in duration) the scholars spend three hours a day in the workshop. This system, it is said, has produced excellent results.

\section{NOTES}

THE Council of the Royal Meteorological Society have arranged to hold at 25 Great George Street, Westminster (by permission of the Council of the Institution of Civil Engineers), on March 19-22 next, an Exhibition of Instruments connected with atmospheric physics invented during the last ten years, especially those used for actinic and solar radiation observations. The Exhibition Committee invite the co-operation of all who may be able and willing to send contributions. The Committee will also be glad to show any new meteorological instruments or apparatus invented or first constructed since last March ; as well as photographs and drawings possessing meteorological interest.

We learn that Prof. Fitzgerald and Mr. Trouton have been conducting experiments confirmatory of Hertz's magnificent work. Lately, using parabolic mirrors after the manner Hertz recently described, they have observed the phenomenon of the polarization of radiations by reflection from a wall 3 feet thick. They observed long ago, and exhibited publicly at the opening meeting of the Experimental Science Association last November, that stone walls are quite transparent to these radiations, as they 